\title{
Simulation of aerosol optical properties over a tropical urban site in India using a global model and its comparison with ground measurements
}

\author{
D. Goto ${ }^{1}$, K. V. S. Badarinath ${ }^{2}$, T. Takemura ${ }^{3}$, and T. Nakajima ${ }^{1}$ \\ ${ }^{1}$ Atmosphere and Ocean Research Institute, University of Tokyo, Kashiwa, Chiba, Japan \\ ${ }^{2}$ Atmospheric Science Section, National Remote Sensing Centre, Hyderabad, India \\ ${ }^{3}$ Research Institute for Applied Mechanics, Kyusyu University, Kasuga, Fukuoka, Japan \\ Received: 8 November 2010 - Revised: 23 May 2011 - Accepted: 30 May 2011 - Published: 31 May 2011
}

\begin{abstract}
Aerosols have great impacts on atmospheric environment, human health, and earth's climate. Therefore, information on their spatial and temporal distribution is of paramount importance. Despite numerous studies have examined the variation and trends of $\mathrm{BC}$ and $\mathrm{AOD}$ over India, only very few have focused on their spatial distribution or even correlating the observations with model simulations. In the present study, a three-dimensional aerosol transport-radiation model coupled with a general circulation model. SPRINTARS, simulated atmospheric aerosol distributions including BC and aerosol optical properties, i.e., aerosol optical thickness (AOT), Ångström Exponent (AE), and single scattering albedo (SSA). The simulated results are compared with both BC measurements by aethalometer and aerosol optical properties measured by ground-based skyradiometer and by satellite sensor, MODIS/Terra over Hyderabad, which is a tropical urban area of India, for the year 2008. The simulated AOT and AE in Hyderabad are found to be comparable to ground-based measured ones. The simulated SSA tends to be higher than the ground-based measurements. Both these comparisons of aerosol optical properties between the simulations with different emission inventories and the measurements indicate that, firstly the model uncertainties derived from aerosol emission inventory cannot explain the gaps between the simulations and the measurements and secondly the vertical transport of $\mathrm{BC}$ and the treatment of BC-containing particles can be the main issue in the global model to solve the gap.
\end{abstract}

Keywords. Atmospheric composition and structure (Aerosols and particles)

Correspondence to: D. Goto (goto@aori.u-tokyo.ac.jp)

\section{Introduction}

Atmospheric aerosols have great impacts on the environment, human health, and earth's climate (Forster et al., 2007). In Asia, especially, atmospheric black carbon (BC) emissions are modulated by anthropogenic activities related to fossilfuel combustion, biomass burning and industrial activities (Ramanathan et al., 2008). Also South Asia, apart from other industrial regions in the world such as North America and Europe, is located in subtropical or tropical regions where dry and wet seasons arrive periodically. In the dry season, biomass burning and other combustion processes often occur and emit a large amount of $\mathrm{BC}$ and organic carbon (OC) in the atmosphere (Bond et al., 2004). Biomass burning has been reported to be the main cause of the dense brown clouds that plague South Asia each winter and affects the health of people inhaling the pollutants, causing bronchitis and asthma (Gustafson et al., 2009). BC, which is the optically absorbing part of carbonaceous aerosols, has significant optical and radiative properties, as compared to the other constituents, i.e., sulfate and nitrate. The $\mathrm{BC}$ emission is the second strongest impact on global warming, next to carbon dioxide emission according to Ramanathan and Carmichael (2008); it can heat the atmosphere and then can cause changes in the atmospheric circulation (Tripathi et al., 2007). However, the radiative effects of $\mathrm{BC}$ are one of the largest uncertainties in climate modeling (Andreae et al., 2005; Ramanathan et al., 2007). In order to improve the model simulations, measurements of both BC and aerosol optical information are required. Several studies on continuous and simultaneous measurements of both BC and aerosol optical information over the South-Asian region are reported in literature (Ganguly et al., 2006; Sreekanth et al., 2007; Safai et al., 2007; Gadhavi and Jayaraman, 2010; Singh et al., 2010). Validation studies on aerosol model simulations with these measurements

Published by Copernicus Publications on behalf of the European Geosciences Union. 
has been less attempted in this region except for few studies (Adhikari et al., 2007), which validated their simulation results with the observed ones over South Asia during almost one year.

Evaluation of simulated aerosol optical properties in global models with measurements is very important for proper estimation of the aerosol radiative forcing. In the estimation of the aerosol radiative focing, the AOT and the SSA are two important parameters. In the present study, observed data on these parameters in Hyderabad, which is located in a tropical urban area of India (Badarinath et al., 2007a, b), are used for model evaluation by comparing them with simulated aerosol optical properties using a global aerosol model, SPRINTARS (Takemura et al., 2000, 2002, 2005, 2009).

\section{Methodology}

\subsection{Data collection}

The study area of Hyderabad, India is located between $17^{\circ} 10^{\prime}$ and $17^{\circ} 50^{\prime} \mathrm{N}$ and $78^{\circ} 10^{\prime}$ and $78^{\circ} 50^{\prime} \mathrm{E}$. Hyderabad is the fifth largest city of India, highly urbanized with population of 5751780 inhabitants (census 2001). The city is influenced not only by vehicular pollutants, but also by industrial as well as biomass-burning emissions. The climate of the region is semi-arid with a total rainfall of $\sim 700 \mathrm{~mm}$ occurring mostly during the monsoon season in the June-October period. The climatology of the area experiences four dominant seasons each year, winter (December-February), premonsoon (March-May), monsoon (June-September), and post-monsoon (October-November). The measurements reported in this work were carried out under clear-sky conditions in the premises of the National Remote Sensing Centre (NRSC) campus located at Balanagar $\left(17^{\circ} 28^{\prime} \mathrm{N}\right.$ and $\left.78^{\circ} 26^{\prime} \mathrm{E}\right)$ well within the urban center of Hyderabad.

$\mathrm{BC}$ aerosols measurements were carried out using seven channels aethalometer (model AE31, Magee Scientific, USA) at NRSC. The aethalometer uses quartz fiber filter tape through which air is passed for a fixed amount of time (typically $5 \mathrm{~min}$ ) with a selected constant flow rate (2.91 per minute). At the end of each measurement cycle, changes in the filter transmission at seven wavelengths $(370 \mathrm{~nm}, 470 \mathrm{~nm}$, $520 \mathrm{~nm}, 590 \mathrm{~nm}, 660 \mathrm{~nm}, 880 \mathrm{~nm}$ and $950 \mathrm{~nm}$ ) are recorded. The $880 \mathrm{~nm}$ channel is considered as standard channel for BC measurement (Wiengartner et al., 2003). BC mass concentrations are estimated by the change in transmittance of this quartz fiber tape over which the deposition of the particles takes place. The beam attenuation (ATN) provides a measure of the absorbing mass. The mass concentration of BC is obtained from an incremental ATN between two measurements using the effective specific mass absorption cross-section value of $16.6 \mathrm{~m}^{2} \mathrm{~g}^{-1}$ for $880 \mathrm{~nm}$ channel for the $\mathrm{BC}$ deposited on the filter area of the sample spot and the flow rate. The uncertainty in $\mathrm{BC}$ measurement will be in the range $0.040-0.060 \mu \mathrm{g} \mathrm{m}^{-3}$. The limitations and uncertainties of aethalometer in $\mathrm{BC}$ measurements and corrections needed are well documented in the recent literature (Hansen et al., 1984; Arnott et al., 2005; Schmid et al., 2006).

Aerosol observations were carried out using a PREDE Sun/sky radiometer (POM-01L, PREDE Incorporated, Japan) during January-December 2008. This instrument is widely used in the SKYNET aerosol radiation network in the world (http://atmos.cr.chiba-u.ac.jp/aerosol/skynet) for Sun/sky observation. This instrument makes measurements of both direct and diffuse sky radiances at pre-defined scattering angles at regular intervals. The Sun/sky radiometer was operated on clear-sky days at 10-min interval. The Sun/sky radiance data were analysed with the radiative transfer inversion code SkyRad Pack version 4.2 (Nakajima et al., 1996; http://www.ccsr.u-tokyo.ac.jp/ clastr/) to retrieve AOT, AE, SSA and volume size distribution. AOT is calculated on the basis of the Beer-Lambert-Bouger law with correction for Rayleigh scattering, the change of Sun-Earth distance, and ozone optical depth. The sky radiometer was operated in disc scan mode to estimate solid view angles at different wavelengths as part of a calibration procedure recommended by the manufacturer. Detailed calibration and data reduction procedures for this instrument were described elsewhere (Nakajima et al., 1996; Pandithurai et al., 2007).

\subsection{Model description}

In this study, we use a global three-dimensional aerosol transport-radiation model, the Spectral Radiation-Transport Model for Aerosol Species (SPRINTARS), which is described elsewhere (Takemura et al., 2000, 2002, 2005, 2009). The SPRINTARS has been implemented in an atmospheric general circulation model (AGCM) developed by the Center for Climate System Research of the University of Tokyo, National Institute for Environmental Studies, and the Frontier Research Center for Global Change (K-1 Model Developers, 2004; hereafter referred to as MIROC AGCM). The version of SPRINTARS is 3.84, which is the latest version since August 2010. In this study, we use T42 horizontal resolution (approximately $2.8^{\circ}$ by $2.8^{\circ}$ in latitude and longitude) and 20 layers of the vertical resolution. The time step is set to $20 \mathrm{~min}$. The model calculates mass mixing ratios of the main tropospheric aerosols, i.e., carbonaceous aerosol (BC and $\mathrm{OC}$ ), sulfate, soil dust, sea salt, and the precursor gases of sulfate, i.e., sulfur dioxide $\left(\mathrm{SO}_{2}\right)$ and dimethylsulfide. The aerosol transport processes include emission, advection, diffusion, sulfur chemistry, wet deposition, and gravitational settling. In all experiments, the monthly averaged global distributions for sea-surface temperature (SST) and sea ice were provided by Hadley Centre, Met Office, UK. For proper simulations of the aerosol distribution, all experiments were conducted with NCAR/NCEP six-hourly nudged meteorological fields on winds, water vapor, and temperature. 


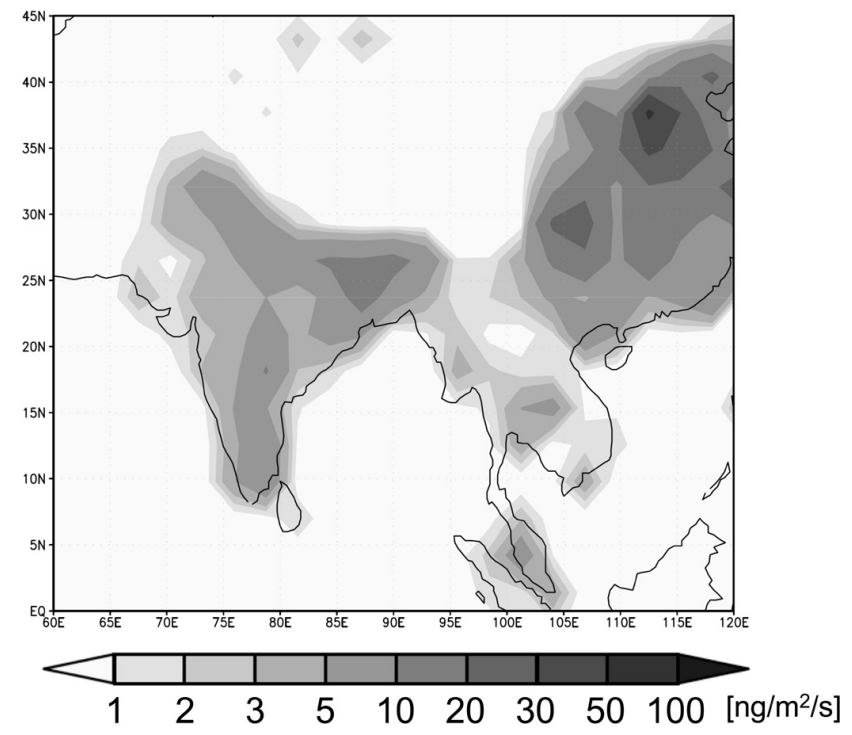

Fig. 1. Mean annual BC emissions for 2008 as used in the AeroCom standard experiment.

The radiation transfer with a k-distribution scheme, MSTRN-8, in the MIROC AGCM can handle scattering, absorption, and emission by aerosol and cloud particles, as well as absorption by gaseous constituents (Nakajima et al., 2000). The particles are treated as external mixtures except for carbonaceous aerosols. The secondary OC and $50 \% \mathrm{BC}$ mass from fossil fuel source are treated as externally mixed particles, but other carbonaceous particles are treated as internal mixtures of BC and primary OC. For soil dust and sea salt aerosols, mixing ratios are calculated for various size bins from 0.1 to $10 \mu \mathrm{m}$ (Takemura et al., 2009). On the other hand, for carbonaceous and sulfate aerosols, the dry mode radii are set to 0.1 and $0.0695 \mu \mathrm{m}$, respectively (Takemura et al., 2002). Aerosol densities are set to the same values as Takemura et al. (2002). The scattering properties by Mie theory used in this study are described elsewhere (Schutgens et al., 2010).

Emission inventories of aerosols (primary OC and BC) and its precursors $\left(\mathrm{SO}_{2}\right)$ used in the model simulations are widely used in the AeroCom (AC) project. The anthropogenic primary organic aerosol and $\mathrm{BC}$ emissions are based on Bond et al. (2004). The spatial distribution of anthropogenic BC emission inventories in the $\mathrm{AC}$ emission inventory is shown in Fig. 1. The anthropogenic $\mathrm{SO}_{2}$ emissions are based on EDGAR 32FT2000 database (http://www.pbl.nl/en/themasites/edgar/ emission_data/edgar_32ft2000/index.html). Biomass burning emissions in each month is based on the fire maps derived from MODIS. The oxidant concentrations such as ozone and hydroxyl radical, which are not predicted in SPRINTARS but are needed to calculate sulfate chemistry, are given by a global chemical transport model, CHASER by Sudo

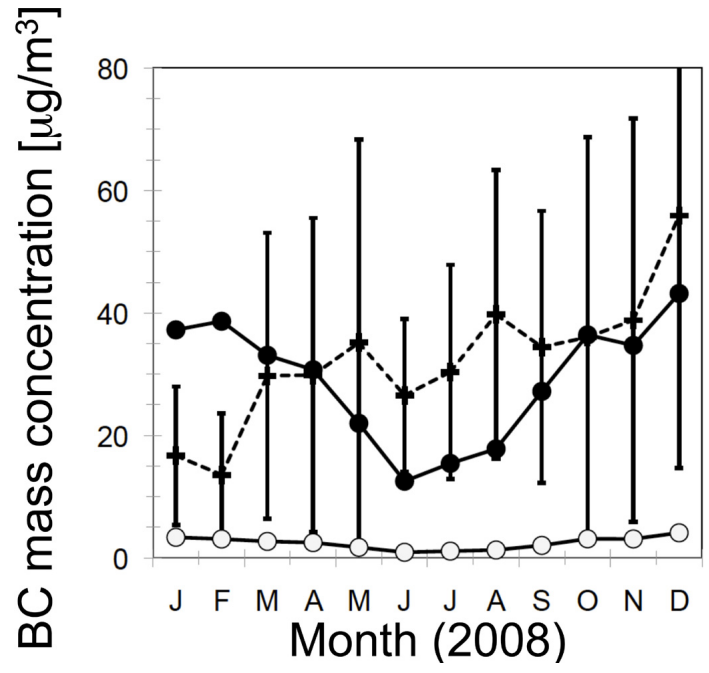

Fig. 2. BC mass concentration in Hyderabad for the year 2008. There are two simulations: SPRINTARS with the AeroCom emissions (solid line with white circles) and with the modified emissions by scaling a factor of 20 around Hyderabad (solid line with black circle) and skyradiometer measurements (dashed line with crosses).

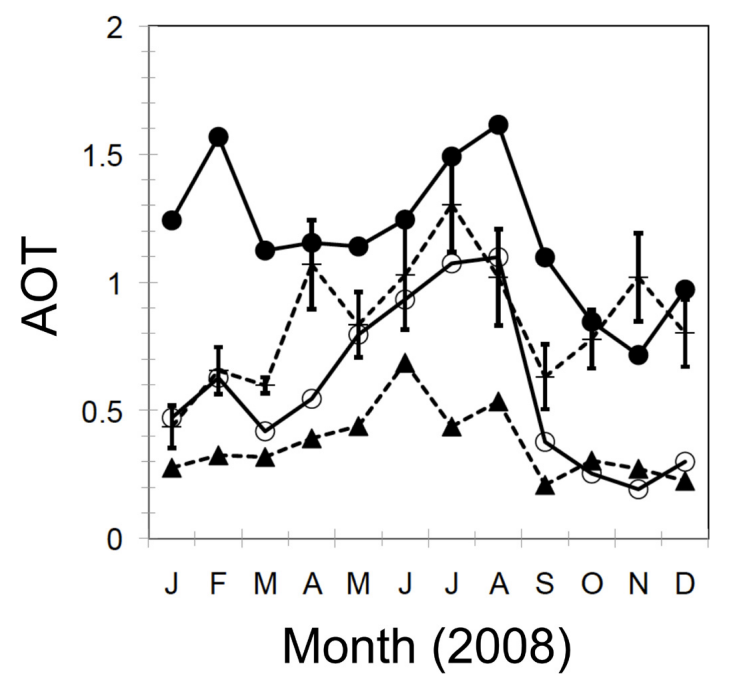

Fig. 3. As in Fig. 1, but for AOT except for MODIS/Terra observations (dashed line with black triangles).

et al. (2002), which also was implemented in the MIROC AGCM. In addition to the standard AC emission inventory, we have added scaling factor of 20 to the AC inventory in the grid including the Hyderabad measurement site and generated modified AC emission inventory. This has been carried out to account for the higher $\mathrm{BC}$ concentrations over the measurement site compared to the standard $\mathrm{AC}$ emission inventory. Model simulations are carried out with the standard AC emission inventory and the modified AC emission inventory. 


\section{Simulation (AC emission)}

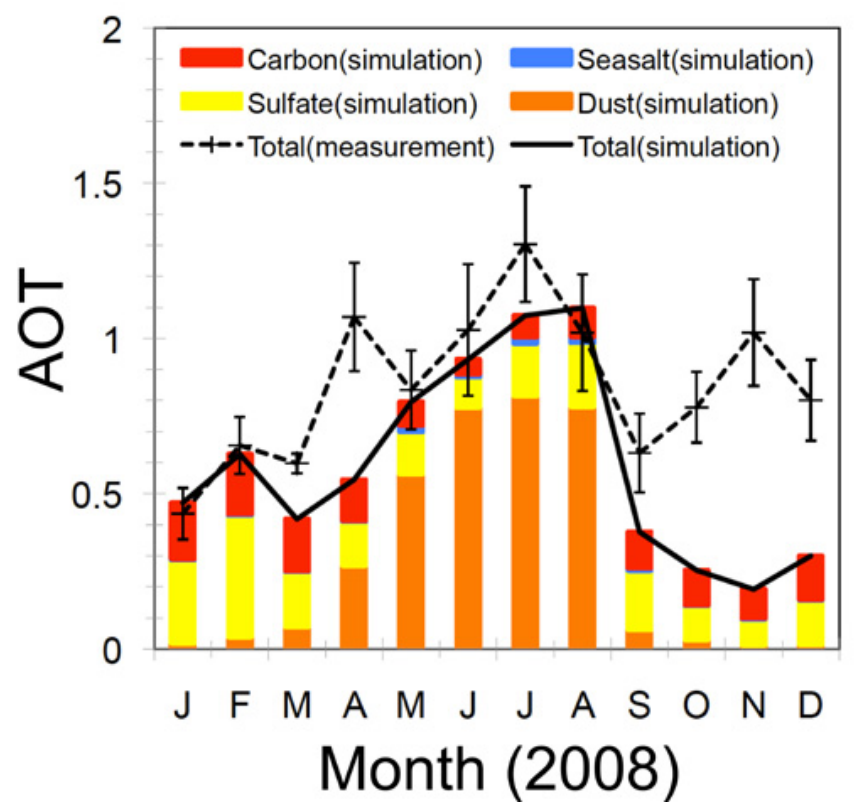

Simulation (Modified AC emission)

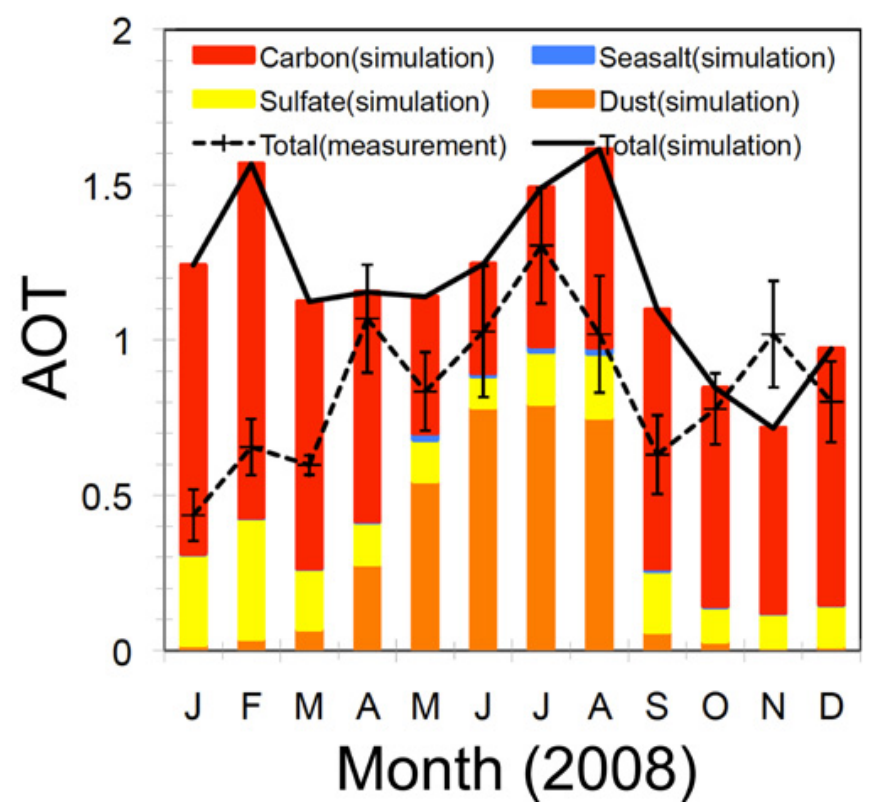

Fig. 4. Model simulation of mean monthly AOTs for the year 2008 with ranging atmospheric composition, i.e., dust with orange, sulfate with yellow, carbonaceous with red and sea salt with blue. The measurement values are shown in dashed line.

\section{Results and discussion}

BC mass concentrations near the surface in Hyderabad are compared with model simulations and are shown in Fig. 2. $\mathrm{BC}$ is the strongest light-absorbing aerosol and it can have a great impact on the SSA and then radiative fluxes. The observed BC in Hyderabad is significantly higher compared to other areas around India and comparable to New Delhi (Beegum et al., 2009). The simulated BC with the standard $\mathrm{AC}$ emission inventory is significantly underestimated compared to the ground-based measured $\mathrm{BC}$ by a factor of 20 . We modified the standard $\mathrm{AC}$ emission of $\mathrm{BC}$ by scaling a factor of 20 only around Hyderabad to bring parity between simulated $\mathrm{BC}$ and ground measured $\mathrm{BC}$. The model simulated BC with the modified $\mathrm{AC}$ emission is closer to the observed $\mathrm{BC}$ in monthly averages within the measured variations except for January and February. During these two winter months, lower values of $\mathrm{BC}$ are observed compared to simulations using the modified BC emission. Previous studies over Hyderabad (Latha and Badarinath, 2005) as well as over India (Sreekanth et al., 2007; Rastogi and Sarin, 2009; Singh et al., 2010) suggest that the variation of measured BC is minimum during the wet season and maximum during winter even though the magnitude of the $\mathrm{BC}$ concentration varies in the year due to anthropogenic factors. These factors may cause some difficulties both in making a corrected monthly variation in $\mathrm{BC}$ emission inventory for each year and thus in simulating $\mathrm{BC}$ aerosol distributions.
The ground-based measured AOTs tend to be higher than MODIS/Terra-retrieved AOTs with monthly-averages ranging from 0.2 to 0.8 as shown in Fig. 3. These differences are sometimes found all over the world because MODISretrieved AOTs over land include large uncertainties (Prasad and Singh, 2007). Although the magnitudes of the AOT are different from each result, the seasonal variations, which represent lower AOTs during winter and higher AOTs during monsoon, are generally found in both the simulations and the measurements. These variations in AOT are associated with long-range transport of aerosols from dust storms, biomass burning besides local sources (Kaskaoutis et al., 2009; Badarinath et al., 2007a, 2010) The model simulated AOT values with the standard AC emission are in between ground-based retrieved AOT and satellite-retrieved AOT, although the simulated ones are underestimated only in October and November. On the other hand, the simulated AOT values by using the modified $\mathrm{BC}$ emission inventory are higher than those with the standard AC emission as we can expect. However, they tend to be higher than the groundbased observed AOT values especially in January and February as observed in $\mathrm{BC}$ variations. In winter, the differences in AOT between the simulations and the measurements are associated with those in BC mass concentration at the surface as shown in Fig. 2. During the monsoon season, the simulated AOT values with the modified AC emission are higher than the measured ones with the difference of more than 0.1, even though the simulated BC mass concentrations at the surface are within the measured variations. The 
(a) Simulation (AC emission)

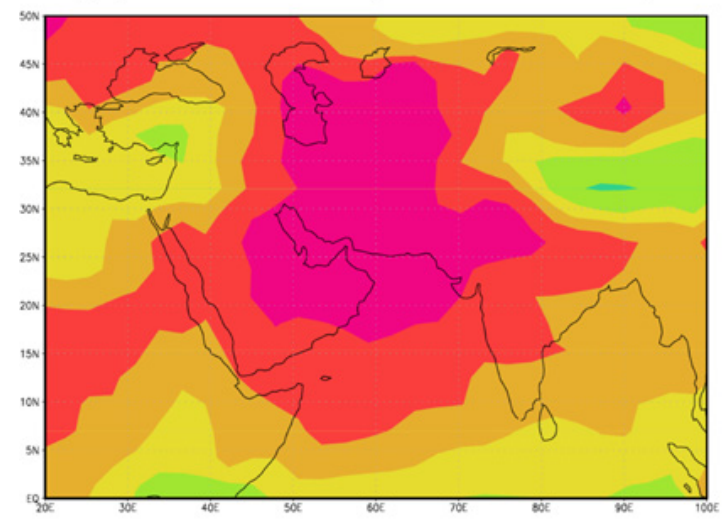

(b) Simulation (Modified AC emission)

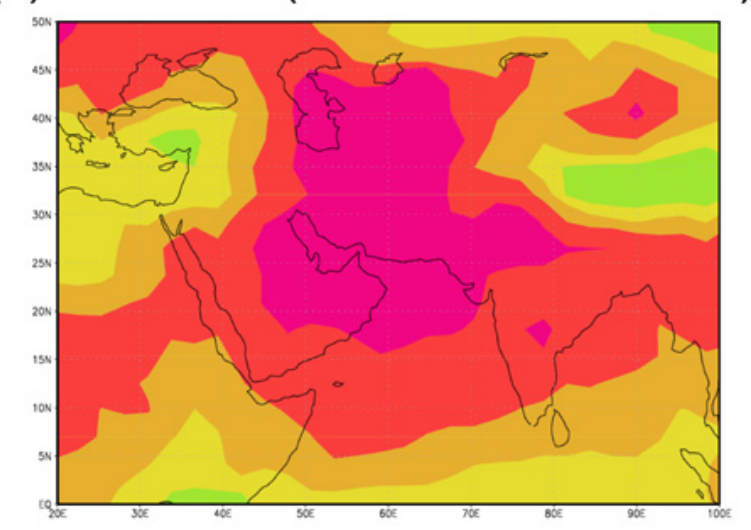

(c) MODIS/Terra

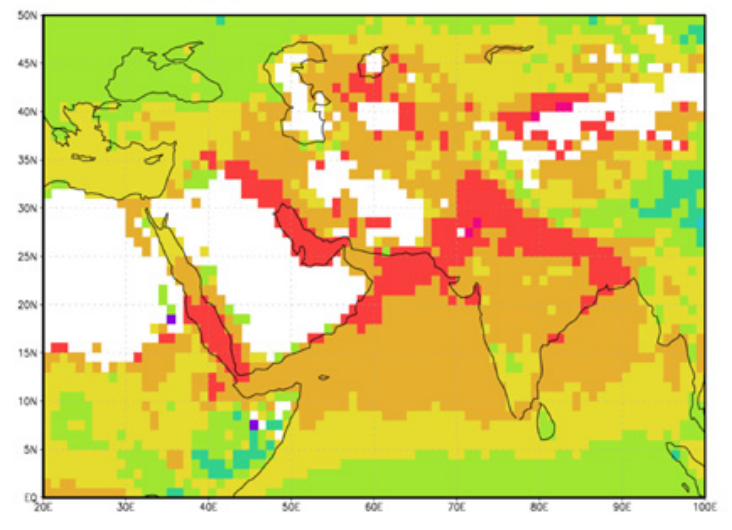

1

0.5

0.3

0.2

0.1 0.05

0.03 0.02 0.01

(b) Model

Fig. 5. Mean annual AOT distribution around India for the year
simulation with modified AC emission inventory. (c) MODIS/Terra.

annual-mean AOT is calculated to be 0.59 in the simulation with the AC emission, 1.18 in the simulation with the modified emission, 0.85 in the ground-based observation, and 0.37 in the MODIS/Terra retrieval. To investigate aerosol composition, we show simulated AOTs in terms of chemical species (Fig. 4). Figure 4 indicates that an increase in AOT around Hyderabad during April to August corresponds to an increase in dust component. The summertime high AOTs correspond to dust composition in our simulation with a maximum of 0.81 . This increased dust is due to long range transport of aerosols from dust storm events located far away at $\sim 2000 \mathrm{~km}$ over region covering Iran and Pakistan as shown in satellite observation of Fig. 5 and previous studies (e.g., Badarinath et al., 2007a). In annual-averages, the AOT around western India is affected by such dust storms from the Middle East Asia. These higher AOTs over the Middle East Asia are also obtained both by model and MODIS/Terra, despite the large spatial difference. Comparison in AOT due to carbonaceous aerosol between two different simulations shows that the annual average AOTs of the carbonaceous aerosol range from 0.12 (AC) to 0.71 (modified AC). The difference in monthly-average AOT values between two simulations is calculated to be 0.30 for the wet season corresponding to June and 0.94 for February.

Model-predicted AEs in both the emission inventories are very similar to observed $\mathrm{AE}$ in term of the magnitudes and seasonality (Fig. 6). The differences in AE between simulations with two emission inventories exist during the wet season, because of an increase in OC of high scattering efficiency as associated with an increase in the BC emission. Model-simulated SSAs in the standard AC emission tend to be higher than the simulated ones in the modified AC emission and observed SSAs, whereas the seasonality of the simulated SSAs in the AC emission is comparable to the observed ones except for January, February, and March. The skyradiometer-retrieved SSA may have errors due to the retrieval algorithm as suggested in literature (Che et al., 2008). The magnitudes of the simulated SSA with the modified AC emission are better than those with the standard AC emission, whereas the seasonality is not good especially during summer. This is because the increase in SSA during summer is primarily caused by an increase in scattering components 


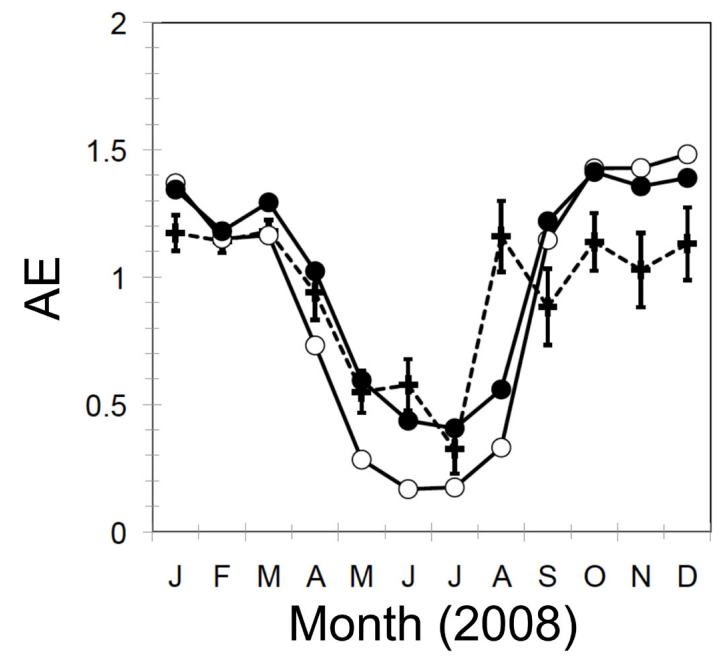

Fig. 6. Monthly variations in AE from two model simulations with the AC emissions (solid line with white circles), modified AC emissions (solid line with black circles) and skyradiometer observations (dashed line with crosses) for the year 2008.

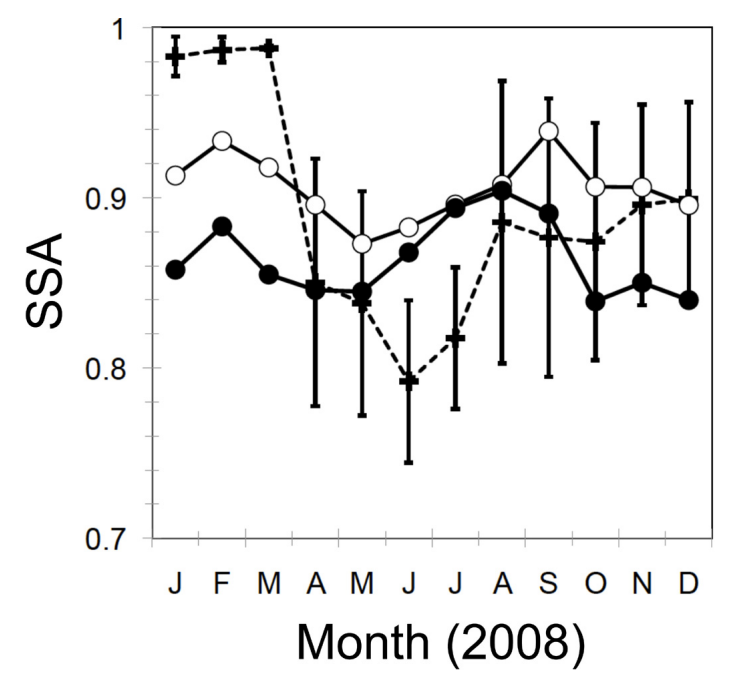

Fig. 7. As in Fig. 6, but for SSA.

associated with aerosol's hygroscopic growth, which can give larger AOT as indicated in Fig. 4. The differences in SSA between model simulations and observations may be caused by treatment of the mixing process between $\mathrm{BC}$ and other scattering components, which can have a large impact on SSA values in the range of \pm 0.05 (Shiraiwa et al., 2008).

Finally, the correlation between AE-SSA and BC-SSA are investigated to know how columnar SSA is determined by $\mathrm{BC}$ or dust components and how $\mathrm{BC}$ aerosols at the surface do affect the columnar SSA values. Figures 8 and 9 show scatter plots of AE-SSA and BC-SSA with the measurements and the simulations using two emission inventories over Hyderbad in 2008 except for January to March due to unreli-

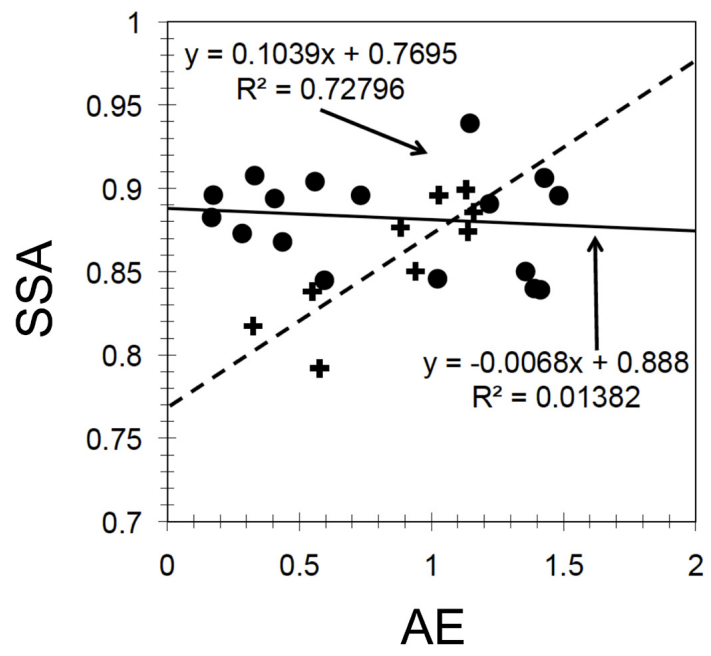

Fig. 8. Scatter plot of AE vs SSA over Hyderabad in 2008. Black circles indicate simulations both with the AC and the modified emissions and crosses indicate observations. The lines are best fits to the data points (thick line: black circles, dashed line: crosses).

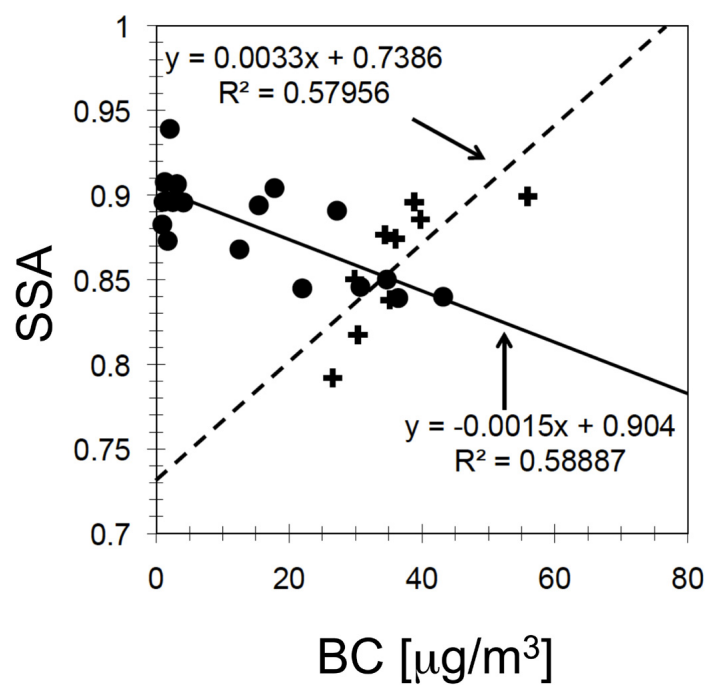

Fig. 9. As in Fig. 8, but for a scatter plot of BC vs. SSA.

able values of measured SSA in these month. In Fig. 8, the positive trend indicates that columnar absorption is determined primarily by large-size absorbing particles, that is dust, whereas the negative trend shows that columnar absorption is determined primarily by small-size absorbing particles, that is BC. The correlation between AE and SSA in the measurements is positive with a regression slope of +0.10 and a correlation coefficient $\left(R^{2}\right)$ of 0.73 , whereas that in the simulations is slightly negative with a regression slope of -0.01 and a $R^{2}$ of 0.01 . The reverse trend of AE-SSA between the simulations and the measurements indicates differences in contributions of columnar BC in the small particle to columnar absorption over Hyderabad. Other finding is 
that model results do not have a correlation between $\mathrm{AE}$ and SSA, which is so different from the measurement results. In Fig. 9, the positive correlation between BC and SSA suggests that increases in $\mathrm{BC}$ at the surface do not correspond to decreases in SSA in the column burden, that means that surface $\mathrm{BC}$ concentration is not the major factor to determine the columnar variations in absorption. The negative correlation suggests that changes in $\mathrm{BC}$ at the surface could strongly modulate the columnar absorption. The correlation between $\mathrm{BC}$ and SSA in the measurements is positive with a regression slope of +0.00 and a $R^{2}$ of 0.58 , whereas that in the simulations is slightly negative with a regression slope of -0.00 and a $R^{2}$ of 0.59 . The reverse trend of BC-SSA between the simulations and the measurements indicates differences in response of $\mathrm{BC}$ at the surface to column absorption over Hyderabad.

These results lead us to the conclusion that in the simulations the increase in $\mathrm{BC}$ at the surface causes the increase in columnar absorption and the decrease in columnar SSA values over Hyderabad, whereas in the measurements the increase in $\mathrm{BC}$ at the surface does not cause the increase in columnar absorption and the columnar absorption can be determined not by small-size absorbing particle, BC, but by large-size absorbing particle, dust. This gap can be partly because vertical distributions of the simulated $\mathrm{BC}$ are not matched with those of the measured $\mathrm{BC}$, that is, the simulated $\mathrm{BC}$ at the surface is underestimated due to large vertical convection in the boundary layer. Other possible reason is that the assumed mixing state in the $\mathrm{BC}$ and other particles does not represent that in the real atmosphere, that is the model BC particles may have stronger absorptions. In addition, this is possibly because the global model with the coarse size of the grid $(\sim 300 \mathrm{~km}$ in this study) cannot exactly compare with point observations on the surface. These problems are expected to exist over India in other global models, because detailed validations over India were not performed mainly because the continuous measurements are limited for validating performances of global models, as suggested by Koch et al. (2009), who compared BC simulations from about 20 global models. Furthermore, the aerosol burdens including BC are very high and complex over India compared to other areas (Ramanathan et al., 2008) and thus making it difficult to compare simulation results with measurements.

In order to estimate an impact of the differences in AOT and SSA between the simulations and the measurements on the aerosol direct radiative forcing (ADRF), we estimated the ADRF with an offline radiative transfer model, Rstar, which was developed by Nakajima and Tanaka $(1986,1988)$ and is very similar to the radiation code MSTRN used in this study. Using the averaged values of AOT and SSA from Figs. 3 and 7, the differences in ADRF between the simulations and the measurements at the surface under the clear sky is estimated to be about $+12 \mathrm{~W} \mathrm{~m}^{-2}$ (July-August) and about $+15 \mathrm{~W} \mathrm{~m}^{-2}$ (October-December), respectively. In conclusion, the differences in AOT and SSA between the simula- tions and the measurements can strongly affect the ADRF and the impact of the ADRF is not so small. Therefore, we have to reduce the differences between the simulations and the measurements in order to estimate the proper model calculation of the ADRF.

\section{Conclusions}

In this study, we compared global model simulation of aerosol optical thickness (AOT), Ångström Exponent (AE), and single scattering albedo (SSA) with ground measurements over Hyderabad, a tropical urban site in India. The results of study suggested that:

1. AOT and AE in the model simulations are comparable to ground-based measurements.

2. SSA in the simulations tends to be higher than that in the ground based measurements and has been attributed to a treatment of $\mathrm{BC}$-containing particles in the global model.

One of the largest uncertainties in the simulations is emission inventory, which was changed with different magnitudes in this study to match simulated BC mass concentrations at the surface to measured ones. A comparison between the simulations with the two emission inventories showed that the simulated AOT and SSA in the column were sometimes different from the measured ones. This could be due to vertical transport pattern, assumed optical properties of BC-containing particles, and spatial resolution in model as well as possible measurement errors for SSA values.

Acknowledgements. The authors express their sincere thanks to Dr. Diehl and AeroCom project for providing emission data sets. The Collection 5 MODIS aerosol products from NASA MODIS team, the reanalysis data from NCEP/OAR/ESRL PSD, Boulder, Colorado, USA, and the HadISST data from Hadley Centre, Met Office, UK are gratefully acknowledged. The model simulations were performed using the National Institute for Environmental Studies, Japan, supercomputer system (NEC SX8R/128M16). Part of the authors was supported by projects (RECCA, JAXA/EarthCARE, MEXT/VL for Climate System Diagnostics, MOE/Global Environment Research Fund B-083, NIES/GOSAT, and JST/CREST).

Topical Editor P. M. Ruti thanks two anonymous referees for their help in evaluating this paper.

\section{References}

Adhikary, B., Carmichael, G. R., Tang, Y. H., Leung, L. R., Qian, Y., Schauer, J. J., Stone, E. A., Ramanathan, V., and Ramana, M. V.: Characterization of the seasonal cycle of south Asian aerosols: A regional-scale modeling analysis, J. Geophys. Res., 112, D22S22, doi:10.1029/2006JD008143, 2007.

Andreae, M. O., Jones, C. J., and Cox, P. M.: Strong present-day aerosol cooling implies a hot future, Nature, 435, 1187-1190, 2005. 
Arnott, W. P., Hamasha, K., Moosmuller, H., Sheridan, P. J., and Orgen, J. A.: Towards aerosol light-absorption measurements with a 7-wavelength aethalometer evaluation with a photoacoutis instrument and 3-wavelength Nephelometer, Aerosol Sci. Technol., 39, 17-25, 2005.

Badarinath, K. V. S., Kharol, S. K., Kaskaoutis, D. G., and Kambezidis, H. D.: Case study of a dust storm over Hyderabad area, India: its impact on solar radiation using satellite data and ground measurements, Sci. Total Environ., 384(1-3), 316-332, 2007a.

Badarinath, K. V. S., Kharol, S. K., Kaskaoutis, D. G., and Kambezidis, H. D.: Influence of atmospheric aerosols on solar spectral irradiance in an urban area, J. Atmos. Solar-Terr. Phys., 69, 589-599, 2007b.

Badarinath, K. V. S., Kharol, S. K., Kaskaoutis, D. G., Sharma, A. R., Ramaswamy, V., and Kambezidis, H. D.: Long-range transport of dust aerosols over the Arabian Sea and Indian region - A case study using satellite data and ground-based measurements, Global Planet. Change, 72, 164-181, 2010.

Beegum, S. N., Moorthy, K. K., Babu, S. S., Satheesh, S. K., Vinoj, V., Badarinath, K. V. S., Safai, P. D., Devara, P. C. S., Singh, S., Vinod, U. C., and Pant, D. P.: Spatial distribution of aerosol black carbon over India during pre-monsoon season, Atmos. Environ., 43, 1071-1078, 2009.

Bond, T. C., Streets, D. G., Yarber, K. F., Nelson, S. M., Woo, J.-H., and Klimont, Z.: A technology-based global inventory of black and organic carbon emissions from combstion, J. Geophys. Res., 109, D14203, doi:10.1029/2003JD003697, 2004.

Che, H., Shi, G., Uchiyama, A., Yamazaki, A., Chen, H., Goloub, P., and Zhang, X.: Intercomparison between aerosol optical properties by a PREDE skyradiometer and CIMEL sunphotometer over Beijing, China, Atmos. Chem. Phys., 8, 3199-3214, doi:10.5194/acp-8-3199-2008, 2008.

Forster, P., Ramaswamy, V., Artaxo, P., Berntsen, T., Betts, R., Fahey, D. W., Haywood, J., Lean, J., Lowe, D. C., Myhre, G., Nganga, J., Prinn, R., Raga, G., Schulz, M., and Van Dorland, R.: Changes in Atmospheric Constituents and in Radiative Forcing, in: Climate Change 2007: The Physical Science Basis. Contribution of Working Group I to the Fourth Assessment Report of the Intergovernmental Panel on Climate Change, edited by: Solomon, S., Qin, D., Manning, M., Chen, Z., Marquis, M., Averyt, K. B., Tignor, M., and Miller, H. L., Cambridge University Press, Cambridge, United Kingdom and New York, NY, USA, 2007.

Gadhavi, H. and Jayaraman, A.: Absorbing aerosols: contribution of biomass burning and implications for radiative forcing, Ann. Geophys., 28, 103-111, doi:10.5194/angeo-28-103-2010, 2010.

Ganguly, D., Jayaraman, A., and Gadhavi, H.: Physical and optical properties of aerosols over an urban location in western India: Seasonal variablities, J. Geophys. Res., 111, D24206, doi:10.1029/2006JD007392, 2006

Gustafsson, O., Krusa, M., Zencak, Z., Sheesley, R. J., Granat, L., Engstrom, E., Praveen, P. S., Rao, P. S. P., Leck, C., and Rodhe, H.: Brown Clouds over South Asia: Biomass or Fossil Fuel Combustion?, Science, 323, 495-498, 2009.

Hansen, A. D. A., Rosen, H., and Novakov, T.: The aethalometer: an instrument for the real-time measurements of optical absorption by aerosol particles, Sci. Total Environ., 36, 191-196, 1984.

K-1 Model Developers: K-1 coupled GCM (MIROC) description, K-1 Tech. Rep. 1, edited by: Hasumi, H. and Emori, S., Univ. of
Tokyo, Tokyo, 2004.

Kaskaoutis, D. G., Badarinath, K. V. S., Kharol, S. K., Sharma, A. R., and Kambezidis, H. D.: Variations in the aerosol optical properties and types over the tropical urban site of Hyderabad, India, J. Geophys. Res., 114, D22204, doi:10.1029/2009JD012423, 2009.

Koch, D., Schulz, M., Kinne, S., McNaughton, C., Spackman, J. R., Balkanski, Y., Bauer, S., Berntsen, T., Bond, T. C., Boucher, O., Chin, M., Clarke, A., De Luca, N., Dentener, F., Diehl, T., Dubovik, O., Easter, R., Fahey, D. W., Feichter, J., Fillmore, D., Freitag, S., Ghan, S., Ginoux, P., Gong, S., Horowitz, L., Iversen, T., Kirkevåg, A., Klimont, Z., Kondo, Y., Krol, M., Liu, X., Miller, R., Montanaro, V., Moteki, N., Myhre, G., Penner, J. E., Perlwitz, J., Pitari, G., Reddy, S., Sahu, L., Sakamoto, H., Schuster, G., Schwarz, J. P., Seland, Ø., Stier, P., Takegawa, N., Takemura, T., Textor, C., van Aardenne, J. A., and Zhao, Y.: Evaluation of black carbon estimations in global aerosol models, Atmos. Chem. Phys., 9, 9001-9026, doi:10.5194/acp-9-9001-2009, 2009.

Latha, K. M. and Badarinath, K. V. S.: Seasonal variations of black carbon aerosols and total aerosol mass concentrations over urban environment in India, Atmos. Environ., 39, 4129-4141, 2005.

Nakajima, T. and Tanaka, M.: Matrix formulations for the transfer of solar radiation in a plane-parallel scattering atmosphere, J. Quant. Spectrosc. Radiat. Transfer, 35, 13-21, 1986.

Nakajima, T. and Tanaka, M.: Algorithms for radiative intensity calculations in moderately thick atmospheres using a truncation approximation, J. Quant. Spectrosc. Radiat. Transfer, 40, 51-69, 1988.

Nakajima, T., Tonna, G., Rao, R., Boi, P., Kaufman, Y., and Holben, B. N.: Use of sky brightness measurements from ground for remote sensing of particulate polydispersions. Appl. Optics, 35, 2672-2686, 1996.

Nakajima, T., Tsukamoto, M., Tsushima, Y., Numaguti, A., and Kimura, T.: Modeling of the radiative process in an atmospheric general circulation model, Appl. Optics, 39, 4869-4878, 2000.

Pandithurai, G., Pinker, R. T., Devara, P. C. S., Takamura, T., and Dani, K. K.: Seasonal asymmetry in diurnal variation of aerosol optical characteristics over Pune, western India, J. Geophys. Res., 112, D08208, doi:10.1029/2006JD007803, 2007.

Prasad, A. K. and Singh, R. P.: Comparison of MISR-MODIS aerosol optical depth over the Indo-Gangetic basin during the winter and summer seasons (2000-2005), Remote Sens. Environ., 107, 109-119, 2007.

Ramanathan, V. and Carmicheal, G.: Global and regional climate changes due to black carbon, Nature Geoscience, 1, 221-227, 2008.

Ramanathan, V., Ramana, M. V., Roberts, G., Kim, D., Corriganm, C., Chung, C., and Winker, D.: Warming trends in Asia amplified by brown cloud solar absorption, Nature, 448, 575-579, 2007.

Ramanathan, V., Akimoto, H., Bonasoni, P., Brauer, M., Carmichael, G., Chung, C. E., Feng, Y., Fuzzi, S., Hasnain, S. I., Iyngararasan, M., Jayaraman, A., Lawrence, M. G., Nakajima, T., Panwar, T. S., Ramana, M. V., Rupakheti, M., Weidemann, S., and Yoon, S.-C.: Atmosphere Brown Clouds and Regional Climate Change, Part I of Atmosphere Brown Clouds: Regional Assessment Report with Focus on Asia. Published by the Project Atmosphere Brown Cloud, United National Environment Programme, Nairobi, Kenya, 2008. 
Rastogi, N. and Sarin, M. M.: Quantitative chemical composition and characteristics of aerosols over western India: One-year record of temporal variability, Atmos. Environ., 43, 3481-3488, 2009.

Safai, P. D., Kewat, S., Praveen, P. S., Rao, P. S. P., Momin, G. A., Ali, K., and Devara, P. C. S.: Seasonal variation of black carbon aerosols over a tropical urban city of Pune, India, Atmos. Environ., 41, 2699-2709, 2007.

Schmid, O., Artaxo, P., Arnott, W. P., Chand, D., Gatti, L. V., Frank, G. P., Hoffer, A., Schnaiter, M., and Andreae, M. O.: Spectral light absorption by ambient aerosols influenced by biomass burning in the Amazon Basin. I: Comparison and field calibration of absorption measurement techniques, Atmos. Chem. Phys., 6, 3443-3462, doi:10.5194/acp-6-3443-2006, 2006.

Schutgens, N. A. J., Miyoshi, T., Takemura, T., and Nakajima, T.: Applying an ensemble Kalman filter to the assimilation of AERONET observations in a global aerosol transport model, Atmos. Chem. Phys., 10, 2561-2576, doi:10.5194/acp-10-25612010, 2010.

Singh, S., Soni, K., Bano, T., Tanwar, R. S., Nath, S., and Arya, B. C.: Clear-sky direct aerosol radiative forcing variations over mega-city Delhi, Ann. Geophys., 28, 1157-1166, doi:10.5194/angeo-28-1157-2010, 2010.

Shiraiwa, M., Kondo, Y., Moteki, N., Takegawa, N., Sahu, L. K., Takami, A., Hatakeyama, S., Yonemura, S., and Blake, D. R.,: Radiative impact of mixing state of black carbon aerosol in Asian outflow, J. Geophys. Res., 113, D24210, doi:10.1029/2008JD010546, 2008.

Sreekanth, V., Niranjan, K., and Madhavan, B. L.: Radiative forcing of black carbon over eastern India, Geophys. Res. Lett., 34, L17818, doi:10.1029/2007GL030377, 2007.
Sudo, K., Takahashi, M., Kurokawa, J., and Akimoto, H.: CHASER: A global chemical model of the troposphere: 1. Model description, J. Geophys. Res., 107(D17), 4339, doi:10.1029/2001JD001113, 2002.

Takemura, T., Okamoto, H., Maruyama, Y., Numaguti, A., Higurashi, A., and Nakajima, T.: Global three-dimensional simulation of aerosol optical thickness distribution of various origins, J. Geophys. Res., 105, 17853-17873, 2000.

Takemura T., Nakajima, T., Dubovik, O., Holben, B. N., and Kinne, S.: Single scattering albedo and radiative forcing of various aerosol species with a global three-dimensional model, J. Climate, 15, 333-352, 2002.

Takemura, T., Nozawa, T., Emori, S., Nakajima, T. Y., and Nakajima, T.: Simulation of climate response to aerosol direct and indirect effects with aerosol transport-radiation model, J. Geophys. Res., 110, D02202, doi:10.1029/2004JD005029, 2005.

Takemura, T., Egashira, M., Matsuzawa, K., Ichijo, H., O’ishi, R., and Abe-Ouchi, A.: A simulation of the global distribution and radiative forcing of soil dust aerosols at the Last Glacial Maximum, Atmos. Chem. Phys., 9, 3061-3073, doi:10.5194/acp-93061-2009, 2009.

Tripathi, S. N., Srivastava, A. K., Dey, S., Satheesh, S. K., and Krishnamoorthy, K.: The vertical profile of atmospheric heating rate of black carbon aerosols at Kanpur in northern India, Atmos. Environ., 41(32), 6909-6915, 2007.

Wiengartner, E., Saathoff, H., Schnaiter, M., Streit, N., Bitnar, B., and Baltensperger, U.: Absorption of light by soot particles: Determination of the absorption coefficient by means of aethalometers, J. Aerosol Sci., 34, 1445-1463, 2003. 